\title{
Prison Doctors and Deadly Mistakes
}

\section{Ernest J. Jack}

$\mathrm{D}^{\mathrm{s}}$ ue to high incarceration rates in the United States, about one percent of its adult population rely on correctional services for health care (Wilper, 2009). I am one of those people.

I was diagnosed with untreatable metastatic stomach cancer that was discovered only in its advanced stage (stage IV). Prior to my diagnosis, I had all the symptoms of anemia, which is sometimes a sign of cancer. Signs like fatigue, shortness of breath, muscle aches, stomach pain, racing heart or pulse and dizziness are all indicators that something was wrong (Beers et al., 2008). I reported those symptoms to my provider each time I went on sick call in the prison. According to the Eighth Amendment's prohibition of "cruel and unusual" punishment, the provider has a duty to follow-up on those symptoms (Wilper et al., 2009). For whatever reason, no medical personnel put things together until it was too late. In this short essay, I want to outline what happened with my diagnosis to illustrate what is happening to those of us who depend on our jailers for care.

I have been suffering with my stomach since before 2010. I read through a book called "The Merck Manual of Medical Information" (Beers et al., 2008), and determined that I might have anemia and possibly cancer. However, I had to convince the providers here at Coyote Ridge Correction Center (CRCC) that I had a serious illness. While there is a provider to see the prisoner in most cases, it is only when they say it is necessary that doctors meet with the incarcerated. A provider is like a Registered Nurse and this is who we mostly see.

On 1 June 2013 I noticed that my stool was black. That was not the first time it happened. Because of the medical reading I had done, I was worried. Anemia is a condition in which the blood is low in red cells or in hemoglobin, resulting in paleness, weakness, internal bleeding, and other health problems (Beers et al., 2008). Each of the times before, I used the sick call sheet in the unit. By the time my name showed up for sick call, my stool was back to normal. The provider would give me test strips to take with me for stool samples. Once I had turned the test strips in, I would not hear from anyone and so I assumed that the tests were negative.

So this time I put in a service kite, instead of just signing up for sick call in the unit. This was 2 June 2013. After receiving my kite, the next day, a provider called the unit and asked for the officer to send me in as soon as possible. On the kite I told them "I am really concerned about my stomach 
that's out of shape, like a swelling on the right side that's been there for a while, plus, the last two days, 6-1-13 and 6-2-13 my stool comes out black. Does this have something to do with my stomach?" I was seen on 3 June 2013 and lab work was finally ordered.

The answer to my kite dated 3 June 13. "You will be on call out in 1 week to have blood drawn and then the next week you will be seen by a provider. You can either drop off the stool sample cards when they're completed or you can bring them with you to your appointment for your blood draw". I took them in when it was done. It is hard to get this service. As noted in a study by Wilper and colleagues (2009), only 3.9 percent of prisoners with active medical problems which routinely require blood testing, were provided with that service.

At the clinic, the provider took my vitals (e.g. blood pressure, fever, etc.), and gave me more strips for my stool and told me to turn them in when done. I was called back again for my blood draw and sent back to wait for my provider to call me after all the test results came in.

Having sent a health kite, I was seen faster. That kite left a paper trail for me. Around 12 June 2013, I was again called in to see the provider after all tests came in and that is when he told me that I was anemic and had been bleeding on the inside for more than eight months, requiring a blood transfusion. How did he know that I was bleeding for eight months? He had to see that on my records and if he did then why did he not see that before? Why did he not see me the times that I complained about black stool and other signs that I reported on sick call? The Washington State Department of Corrections website states that "emphasis is placed on early identification of health concerns, care for acute and chronic health problems and preventive care" (Department of Corrections, 2015), but this is certainly not my experience.

The doctor said: "I'm going to get you a wheelchair to get you around until I can get you approved for that blood transfusion. In the meantime, if you feel like you're going to pass out again, come in to sick call and I'll declare an emergency and send you to the hospital in town". Just think, I am bleeding and was sent back to my unit to wait and possibly bleed to death.

On 24 June 2013, after more complaining, the provider finally declared an emergency and I was sent to Kadalic Medical Center for the blood transfusion and more tests. I was given two units of blood. A positron emission tomography (PET) scan, which is similar to an X-ray, revealed 
that I had cancer that was too close to my esophagus for it to be removed. It was too advanced. Had my provider read my results from those earlier tests taken, my cancer might have been in the early stage and I might have been able to get the cancer removed. It is no wonder that cancer is one of the five leading causes of deaths in jail in the United States (Noonan, 2012). In fact, in 2010, cancer was the most common cause of death in prisons (ibid).

I know I am not alone in facing a chronic condition in prison. In the study by Wilper and colleagues (2009), the researchers found that almost 50,000 prisoners had chronic health conditions. But since it takes so long to see anyone, I think prisoners should take it upon themselves to research their illness, then they could convince the provider if they feel they are not making the right diagnoses. They should always try to leave a paper trail.

Two months after the provider declared an emergency, I started my treatment at St. Mary Regional Cancer Center in Walla Walla, Washington. I have since been transferred to Airway Heights Correction Center (AHCC) where I have completed my second cancer treatment because the disease returned.

\section{AFTERTHOUGHT}

I feel that the providers here at CRCC acted recklessly and with deliberate indifference to my serious medical needs. I wrote this piece because I think this is common practice in many instances. Prisoners are made to feel intimidated so they will not complain even when mistakes (sometimes deadly in effect) are common, but we have little power to get better care. When you are in prison, the avenues to get better care are not available and you are stuck with the kind of care I have described.

\section{REFERENCES}

Beers, Mark H., Andrew J. Fletcher, Thomas V. Jones, Robert Porter and Michael Berkwits (eds.) (2008) The Merck Manual of Medical Information: Home Edition, New Jersey: Simon and Schuster.

Department of Corrections, Washington State (2015) Prison Life Health Services. Available at http://www.doc.wa.gov/family/offenderlife/healthservices.asp.

Noonan, Margaret E. (2012) Mortality in Local Jails and State Prisons, 2000-2010 Statistical Tables. Available at http://www.bjs.gov/content/pub/pdf/mljsp0010st.pdf. 
Wilper, Andrew P., Steffie Woolhandler, J. Wesley Boyd, Karen E. Lasser, Danny McCormick, David H. Bor and David U. Himmelstein (2009) "The Health and Health Care of US Prisoners: Results of a Nationwide Survey", American Journal of Public Health, 99(4): 666-672.

\section{ABOUT THE AUTHOR}

Ernest Jack is a 66-year-old disabled Vietnam veteran doing 14 years in Walla Walla State Prison. He is a writer with stories online at www. prisonsfoundation.org and he is hoping for an extraordinary release under the RCW 9.94A.728 as his current release date is in 2023. 